\title{
STRENGTH, DURABILITY AND HYDRAULIC PROPERTIES OF CLAY STABILIZED WITH ECO SAND
}

\author{
AMMAIAPPAN. $\mathbf{M}^{\mathbf{1}}$, MUTHAIYAN. ${ }^{\mathbf{2}}$, M. UMA MAGUESVARI ${ }^{\mathbf{3}}$ \& K. NATARAJAN ${ }^{4}$ \\ ${ }_{1,2}^{1}$ Assistant Professor, Department of Civil Engineering, Rajalakshmi Engineering College,
}

Thandalam, Chennai, India

${ }^{3}$ Associate Professor, Department of Civil Engineering, Rajalakshmi Engineering College,

Thandalam, Chennai, India

${ }^{4}$ Associate Professor, Department of Civil \& Structural Engineering, Annamalai University Chidambaram, India

ABSTRACT
The clayey soils are known to pose severe problems in construction activities which may lead to increase in construction
costs. Mitigation measures as well as repeated and costly maintenance works to be done for soils which are having the
properties of high swelling, shrinkage and very low shear strength. Stabilization process enhances the engineering
properties of the clayey soils. The eco sand is one such an industrial waste product which accounts about 1000 tons per
day derived from cement manufacturing industry. In this study the clay of high compressibility (CH) is blended with eco
sand of various dosages such as $10 \%, 20 \%, 30 \% 40 \%$ \& $50 \%$ by weight of soil. With this optimum dosage, the
strength studies by UCS test, durability studies by conducting wetting drying cycles \& hydraulic properties by studying
the soil water characteristic curve in pressure plate test were investigated. The results showed that the improvement in
clayey soils such parameters have been observed in optimum dosage of eco sand with CI soil.
KEYWORDS: Clayey Soil, Eco Sand, UCS, Durability \& SWCC

Received: May 26, 2020; Accepted: Jun 06, 2020; Published: Jun 30, 2020; Paper Id.: IJMPERDJUN2020205

\section{INTRODUCTION}

Soil Stabilization is a technique that process of blending and mixing materials with a weak soil to improve certain properties of the soil. The process includes the blending of soils to achieve a desired gradation, texture or plasticity of the soil. The most common improvements achieved through stabilization include better soil gradation, reduction of plasticity index or swelling potential and increase the durability and strength. In recent years of development many industrial waste materials have been used as a stabilizing agent of sub grade soil. Industrial development in India poses an important problem of disposal of industrial wastes and the environmental pollution caused by it. The use of some industrial waste materials in foundations is based on technical economical and ecological criteria. One such material that is disposal in tons is the eco sand. Eco sand is one such waste material derived from the cement manufacturing industry. Several million metric tons of used ecosand is disposed as waste. Therefore in this study, ecosand is used as a material for stabilization of soil. Thus the disposal of ecosand would be made easier and the problems due to clay over foundations could also be overcome.

\section{LITERATURE REVIEW}

Dr. Suhail A., A. Khattab,Khawla A, K. Al Juari and Ibrahim M. A. Al-Kiki', Studied the effect of utilization of industrial waste(lime) on some in engineering properties of clayey soil selected from Mosul city. These 
characteristics are unconfined compressive strength, permeability, Soil water characteristic curve and durability.

Dr.Suhail Idrees Khattab and Mohammed Mukhlif Aljibouri studied some of the hydraulic properties (permeability and water retention) of stabilized clayey soil selected area. The optimum results show the stabilized soil suitable as a base course. The permeability of natural soil was found to increase with treatment of industrial waste.

Delwyn G. Fredlund Sheng, and Jidong Zhao examined the possibility of using Soil Water Characteristics Curves (SWCC) for the estimation of in situ soil suction. The paper focuses on the limitations of estimations should be used. The potential range of estimated suction values is known to be large because of hysteresis between drying and wetting SWCCs. However a framework is suggested in this paper for estimating the median value for in situ suction along with a likely range of soil suction values.

\section{MATERIALS AND PROPERTIES}

The two types of soil samples clay of high compressibility $(\mathrm{CH})$ is used in this study. The Soils are collected as per procedure at a depth of about $0.7 \mathrm{~m}$. The soils were testes by as per IS: 2720 (part).Both soils were classified as $\mathrm{CH}$ based on corresponding test results values. The values are tabulated in Table 1.The ecosand were collected from ACC cements madhukkarai; Coimbatore Ecosand is a very fine particle, a bi-product from cement manufacture which can be used to increase the efficiency in Soil. The generation of eco sand is approximately 500tons per day and is disposed as a waste. The production of Ecosand is shown in the form of flow chart,

The use of eco sand rather than extracted or dredged natural sand will help designers and contractors address issues of sustainability. The eco sand has various advantages such as energy efficient, fire resistant, reduction of dead load, environmentally friendly, durable, light weight, low maintenance, and low construction cost. The properties are tabulated in Table 2 .

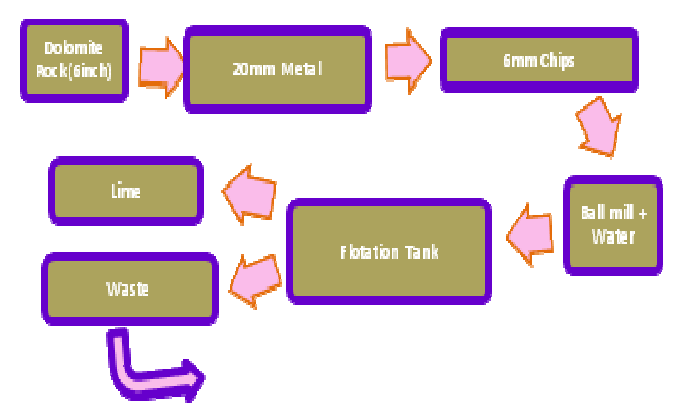

Figure 1

Table 1: Properties of Soil Samples

\begin{tabular}{|l|c|}
\hline \multicolumn{1}{|c|}{ Properties } & Sample CH \\
\hline Liquid Limit, \% & $57 \%$ \\
\hline Plastic Limit, \% & $23 \%$ \\
\hline Shrinkage Limit, \% & $11.67 \%$ \\
\hline Maximum Dry Density (MDD), g / cc & 1.831 \\
\hline Ooptimum Moisture Content (OMC) \% & $20.29 \%$ \\
\hline Unconfined Compressive Strength,( N / $\mathrm{mm}^{2}$ ) & 0.158 \\
\hline Soil dispersion \% & $68 \%$ \\
\hline
\end{tabular}


Table 2: Properties of Eco Sand

\begin{tabular}{|l|c|}
\hline \multicolumn{1}{|c|}{ Properties } & Result \\
\hline Initial moisture content & 4.5 \\
\hline Sieve Analysis & Fine grained sand-poorly graded \\
\hline Specific Gravity & 2.63 \\
\hline $\mathrm{SiO}_{2}$ & $74.12 \%$ \\
\hline $\mathrm{Al}_{2} \mathrm{O}_{3}$ & $3.0 \%$ \\
\hline $\mathrm{Fe}_{2} \mathrm{O}_{3}$ & $1.0 \%$ \\
\hline $\mathrm{MgO}_{2} \mathrm{O}_{2}$ & $0.8 \%$ \\
\hline $\mathrm{Mn}_{2} \mathrm{O}_{3}$ & $0.04 \%$ \\
\hline $\mathrm{Na}_{2} \mathrm{O}$ & $1.3 \%$ \\
\hline $\mathrm{K}_{2} \mathrm{O}_{3}$ & $0.5 \%$ \\
\hline $\mathrm{BaO}$ & $0.5 \%$ \\
\hline
\end{tabular}

\subsection{Experimental Investigation}

The experimental investigation was studied on characteristics of soil plasticity, soil swelling, compaction studies, unconfined compression tests, soil water characteristics curves and durability studies.

Soil Plasticity: The plasticity characteristics such as liquid limit, plastic limit, shrinkage limit was studied with different proportions of the ecosand. The following table shows the plasticity characteristics of soil mixed with various proportions of the eco sand.

Table 3: Atterbergs Limit Values Treated With Eco Sand

\begin{tabular}{|c|c|c|c|c|c|c|}
\hline \% ES & $\mathbf{1 0}$ & $\mathbf{2 0}$ & $\mathbf{3 0}$ & $\mathbf{4 0}$ & $\mathbf{5 0}$ & $\mathbf{6 0}$ \\
\hline $\mathrm{w}_{\mathrm{L}}(\%)$ & 55 & 53 & 50 & 48 & 49 & 52 \\
\hline $\mathrm{W}_{\mathrm{P}}(\%)$ & 23.5 & 24.2 & 25.4 & 26.8 & 26 & 25.2 \\
\hline $\mathrm{w}_{\mathrm{S}}(\%)$ & 12.52 & 13.96 & 14.94 & 15.58 & 15.24 & 14.83 \\
\hline $\mathrm{Ip}(\%)$ & 31.5 & 28.8 & 24.6 & 21.2 & 23 & 26.8 \\
\hline
\end{tabular}

3.2. Soil Swelling Characteristics: The soil swelling characteristics was studied with different proportions of the eco sand.

Table 4: Swelling Index Values Treated With Eco Sand

\begin{tabular}{|c|c|c|c|c|c|}
\hline \% ES & $\mathbf{1 0}$ & $\mathbf{2 0}$ & $\mathbf{3 0}$ & $\mathbf{4 0}$ & $\mathbf{5 0}$ \\
\hline Free Swell & 65 & 60 & 55 & 48 & 52 \\
\hline
\end{tabular}

3.3. Compaction Studies: The compaction tests were conducted on virgin soil treating with different proportions of the eco sand. It is to determine the compaction characteristics (OMC and MDD) accordance with IS 2720 Part VII.

Table 5: OMC \& MDD Values Treated With Eco Sand

\begin{tabular}{|c|c|c|c|c|c|c|}
\hline \% of ES & $\mathbf{0}$ & $\mathbf{1 0}$ & $\mathbf{2 0}$ & $\mathbf{3 0}$ & $\mathbf{4 0}$ & $\mathbf{5 0}$ \\
\hline OMC & 20.29 & 19.45 & 18.34 & 17.54 & 16.27 & 15.85 \\
\hline Dry density & 1.831 & 1.791 & 1.772 & 1.736 & 1.742 & 1.796 \\
\hline
\end{tabular}




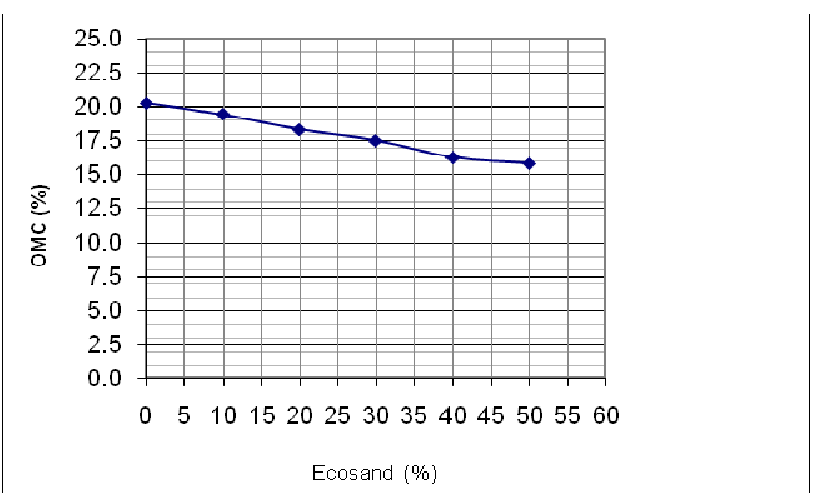

Figure 1: Comparison of OMC With Various \% of Eco Sand.

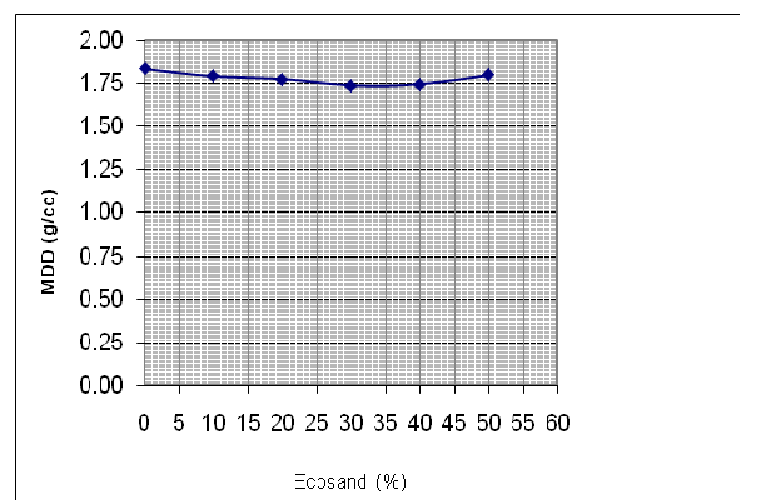

Figure 2: Comparison of Dry Density With Various \% of Eco Sand.

3.4. Unconfined Compression Test: The unconfined compression test was conducted for various percentages namely $8 \%, 10$ $\%, 12 \%, 14 \%$, and $16 \%$, of ES with clay and results have been presented below. The table gives the test values obtained from plotted graphs for various \% of ES.

Table 6: UCC Strength Values for Various \% of ES

\begin{tabular}{|c|c|c|}
\hline Percentage of Resin Added (\%) & Unconfined Compressive Strength N/ Mm & Cohesive Strength N/ $\mathbf{M m}^{\mathbf{2}}$ \\
\hline 10 & 0.158 & 0.79 \\
\hline 20 & 0.167 & 0.84 \\
\hline 30 & 0.180 & 0.90 \\
\hline 40 & 0.197 & 0.99 \\
\hline 50 & 0.177 & 0.89 \\
\hline 60 & 0.162 & 0.81 \\
\hline
\end{tabular}

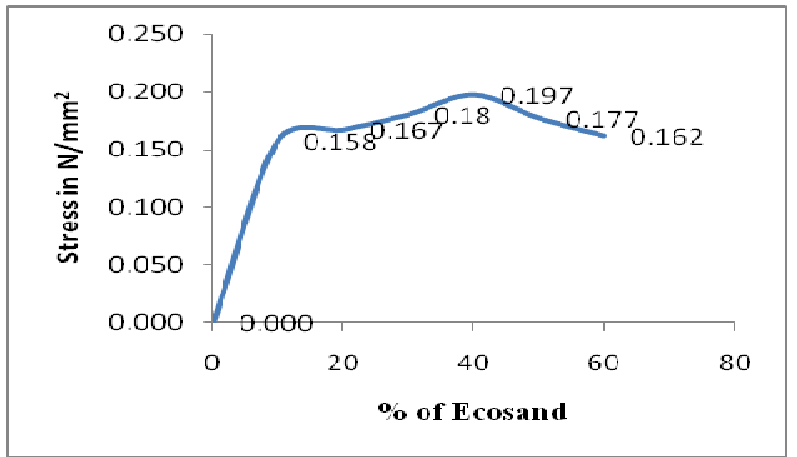

Figure 3: UCC Strength for Various \% of Eco Sand 


\subsection{Soil dispersion Test (Double hydrometer test)}

The double hydrometer test also as soil conservation service laboratory dispersion test was performed to identify the depressiveness of soil. The particle size distribution of the soil is first determined using the standard hydrometer test where the soil is dispersed in distilled water with strong mechanical agitation and chemical dispersant. A parallel hydrometer test is then made on a duplicate soil specimen but without mechanical agitation and without a chemical dispersant. The test was conducted as per USBR 5405. In experimental study, the test was conducted for soil sample with optimum dosage of eco Sand namely $12 \%$.

Table 6 shows the ratio of the dry mass of particles smaller than $0.005 \mathrm{~mm}$ diameter in a test without dispersing agent to the mass of particles smaller than $0.005 \mathrm{~mm}$ in a test with dispersing agent expressed as a percentage.

The Result Obtained from Hydrometer Analysis for a Virgin Soil is Shown in Figure

Table 6: Degree of Dispersion

\begin{tabular}{|c|c|c|}
\hline Sl. No & \% of Dispersion & Degree of Dispersion \\
\hline 1 & $<30$ & Non dispersive \\
\hline 2 & $30-50$ & intermediate \\
\hline 3 & $>50$ & Dispersive \\
\hline
\end{tabular}

From graph: Dispersion value-47\%

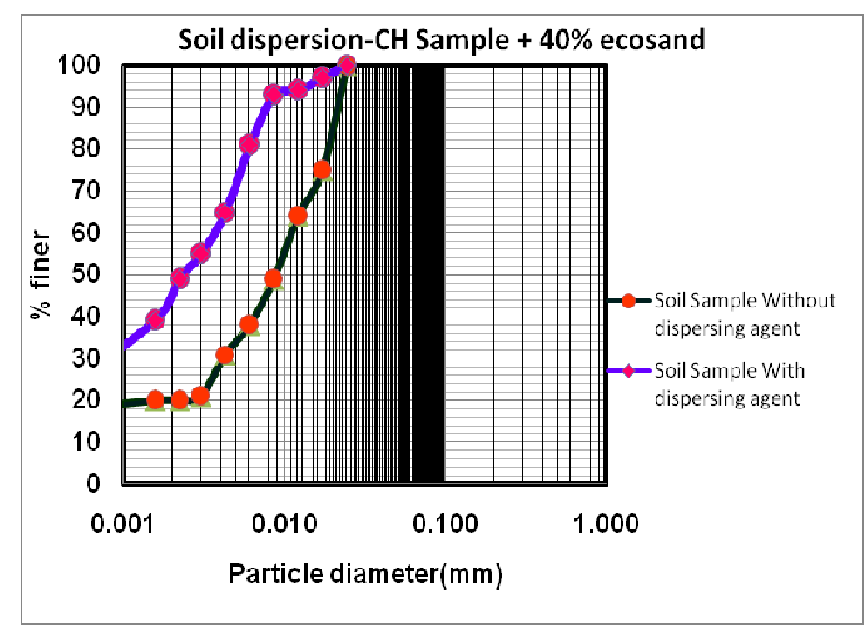

Figure 4: Dispersion Graph With Optimum \% Eco Sand

\subsection{Durability Studies}

Durability studies are conducted by subjecting the soil specimens to alternative wetting and drying processes. ASTM D 559 method is the standard method often used for these wet-dry cycle investigations. According to the ASTM D 559 method the prepared soil specimens are cured and then submerged in water for 5 hours and then oven dried at $120^{\circ} \mathrm{F}$ for 42 hours to complete one wetting / drying cycle. The soil specimens are studied for volumetric change measurements before and after the completion of wetting / drying cycles. The measurements of the vertical deformations are done by using dial gauges on the top and the diametrical changes by pi tape. The test is continued till 21 wetting / drying cycles or till the sample fails.

The control virgin soil survived for only one cycle of durability with a maximum volumetric strain of $60 \%$. In experimental study, the test was conducted for soil sample at different percentages of eco Sand namely $10 \%, 20 \%, 30 \%$ and $40 \%$ of eco Sand mixed with clay. 


\subsection{Hydraulic Properties}

The hydraulic properties of soil such as permeability and soil water characteristic curve were studied.

\section{Permeability test}

The coefficient of permeability is obtained by conducting variable head permeability test. The test was conducted as per IS 2720 (Part 36): 1997.In experimental study, the test was conducted for soil sample with optimum dosage of eco Sand namely $20 \%$.

The coefficient of permeability of vrigin soil is found to be $3.57 \times 10^{\wedge}-7 \mathrm{~cm} / \mathrm{s}$.

\section{Soil Water Characteristic Curve}

Soil-water characteristics curve is one of the important hydraulic properties; it is the relation between water content and soil suction. Total suction is determined by using pressure plate apparatus. ASTM 2008 method is the standard method often used for this test. According to ASTM 2008, a pressure plate extractor was used for a soil metric suction range of 200 $\mathrm{kPa}$ to $1500 \mathrm{kPa}$. The pressure extractor accommodated several soil samples which were in contact with a porous ceramic plate. Once the extractor was sealed, an air pressure was applied to the air space above the samples, and water moved downward from the samples through the plate for collection in a measuring bottle. The samples were then removed, and water content was determined gravimetrically. Gravimetric water content is defined as the ratio of mass of water (mw) to the mass of soil solids (ms).

In experimental study, the test was conducted for soil sample with optimum dosage of ecosand namely $20 \%$.

The relation between total suction and gravimetric suction obtained as a result of pressure plate test for a virgin soil is shown in Figure 5

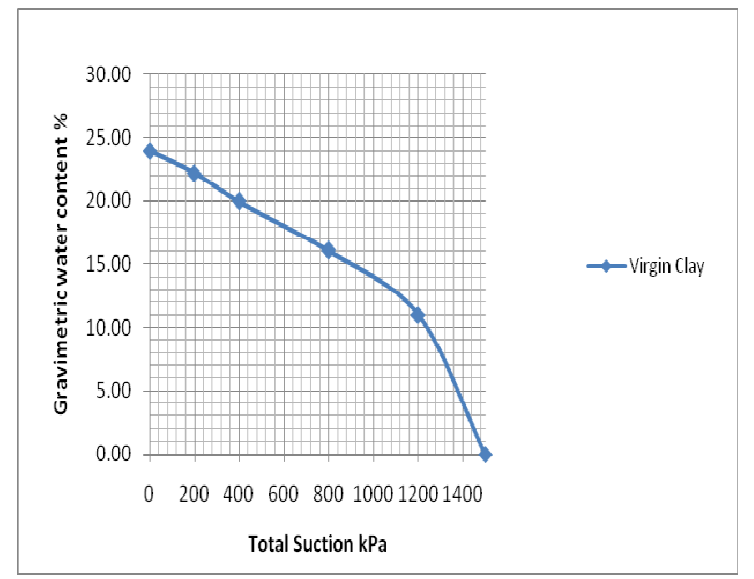

Figure 5: Gravimetric Water Content with Different Total Suction for Virgin Clay.

\section{RESULTS AND DISCUSSIONS}

4.1. Soil Plasticity: The table shows that the value of atterberg's limits, the plasticity index values decreased from 31.5 to 21.2 up to addition of $40 \%$ of ecosand.

4.2. Soil Swelling Characteristics: The table shows that the value of free swell index, the swelling values decreased from $65 \%$ to $48 \%$. 
4.3. Compaction Characteristics: The table shows that the value of optimum and maximum dry density, the result values shows that the optimum moisture content has increased and dry density decreased.

4.4. Unconfined Compression Test: It was observed that the value of shear strength increased from $0.158 \mathrm{~N} / \mathrm{mm} 2$ to $0.197 \mathrm{~N} / \mathrm{mm} 2$ upto addition of $40 \%$ of ecosand then the strength value decresed by increasing the \% of ecosand.So that optimum percentage of Eco Sand is $40 \%$ for increasing shear strength.

Soil dispersion test: It is observed that the dispersive vlaue is decreased from $68 \%$ to $48 \%$ at optimum dosage of ecosand namely $40 \%$.Therefore at optimum dosage of ecosand, the dispersive soil is changest into intemediate dispersive soil.

\subsection{Durability Studies}

The test was conducted for various percentages namely 10\%, 20\%, 30\%and 40\%, of ecosand with clay and results have been presented below. The 7 gives the test values obtained from plotted graphs for various \% of ES.

Table 7: Wet \& Dry Cycles Various \% of Eco Sand

\begin{tabular}{|c|c|c|c|c|c|}
\hline Sl. No & No of Cycles & $\mathbf{1 0} \%$ ES & $\mathbf{2 0} \%$ ES & $\mathbf{3 0} \%$ ES & $\mathbf{4 0} \%$ ES \\
\hline 1 & 0 & 100 & 100 & 100 & 100 \\
\hline 2 & 1 & 60 & 53 & 65 & 79 \\
\hline 3 & 2 & 0 & 15 & 51 & 60 \\
\hline 4 & 3 & - & 0 & 37 & 54 \\
\hline 5 & 4 & - & - & 15 & 47 \\
\hline 6 & 5 & - & - & 0 & 39 \\
\hline 7 & 6 & - & - & - & 22 \\
\hline 8 & 7 & - & - & - & 0 \\
\hline 9 & 8 & - & - & - & - \\
\hline
\end{tabular}

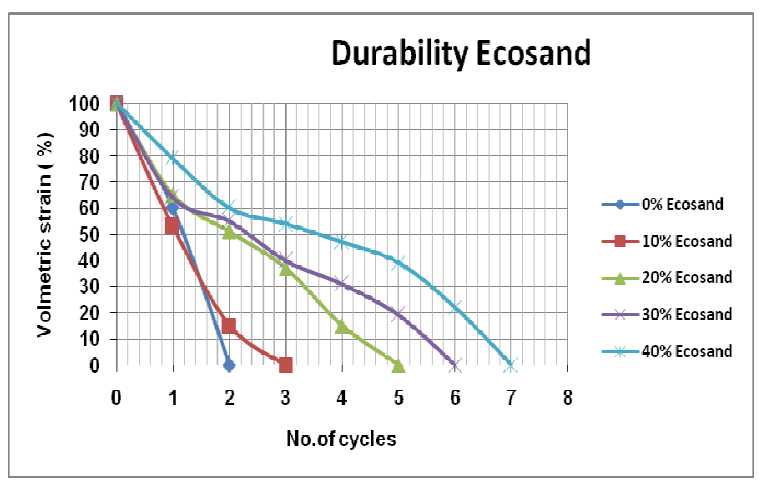

Figure 6: Variation of Volumetric Strain with W / D Cycles for Various \% Eco Sand.

\subsection{Hydraulic Properties}

The hydraulic properties of soil such as permeability and soil water characteristic curve were studied.

Permeability Test: The permeability test was conducted for various percentages namely $10 \%, 20 \%, 30 \%$, and $40 \%$ of ES with clay and results have been presented below.

Figure 7 Shows It is observed that the permeability of soil is increasing due to addition ecosand.

Table 8: Variation of K For Various \% of Eco Sand

\begin{tabular}{|c|c|c|}
\hline Sl. No & \% Eco Sand & Coefficient of Permeability $\mathbf{~ ( C m ~ / ~ s ) ~ X 1 0 ~}$ \\
\hline 1 & 0 & 3.57 \\
\hline 2 & 10 & 4.25 \\
\hline
\end{tabular}




\begin{tabular}{|l|l|l|}
\hline 3 & 20 & 4.89 \\
\hline 4 & 30 & 6.73 \\
\hline 5 & 40 & 6.44 \\
\hline
\end{tabular}

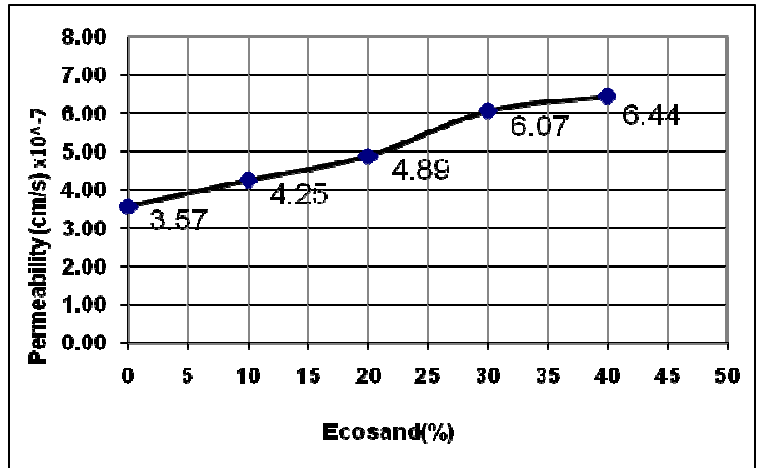

Figure 7: Coefficient of Permeability for Various $\%$ of Eco Sand.

\subsection{Soil Water Characteristic Curve}

According to ASTM 2008, the test was conducted for various suction ranges namely $200 \mathrm{kPa}, 400 \mathrm{kPa}, 800 \mathrm{kPa}$ and $1200 \mathrm{kPa}$ and $1500 \mathrm{kPa}$.for soil sample with optimum dosage of ecosand. The obtained results from analysis are shown in Figure 8.

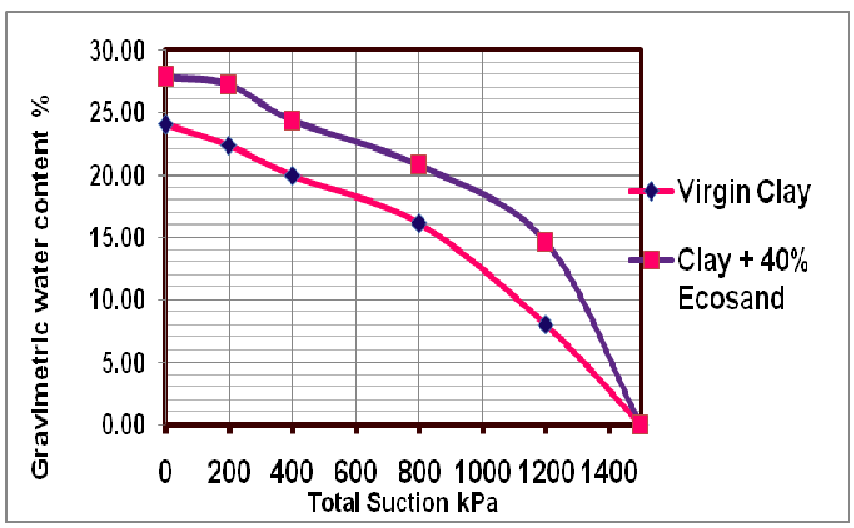

Figure 8: Gravimetric Water Content with Different Total Suction at Optimum Dosage of Eco Sand.

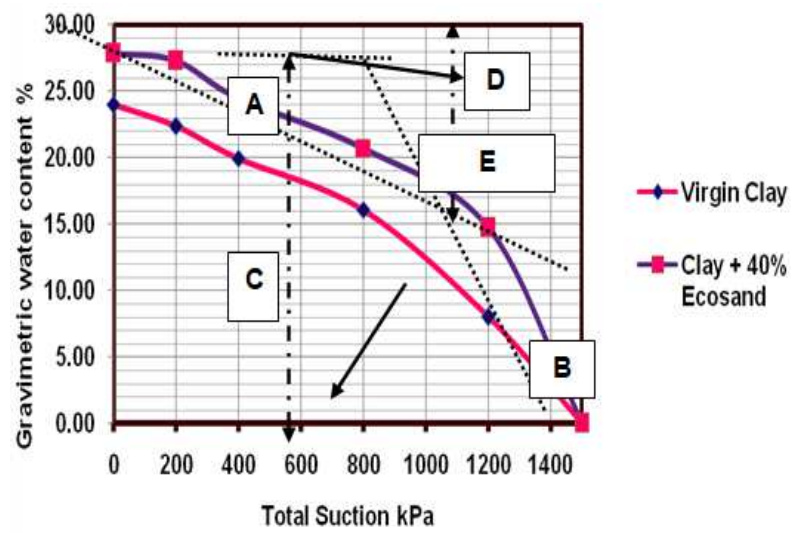

Figure 9: Gravimetric Water Content with Different Total Suction at Optimum Dosage of Eco Sand. 


\section{CONCLUSIONS}

The following conclusions were arrived on comparing the obtained results from previous explanations, presented tables and diagrams.

- It has been observed that $40 \%$ ecosand by weight is found to be the optimum dosage to soil.

- With the increase in the percentage of ecosand in soil, its swelling has decreased from $68 \%$ to $38 \%$.

- With the increase in the percentage of ecosand, the plasticity index of soil has reduced from 34 to 21.

- With the increase in the percentage of ecosand to soil, the optimum moisture content has increased and dry density decreased.

- Addition of ecosand to soil increases the compressive strength about $25 \%$.

- At optimum dosage of ecosand, the soil dispersion value decreased by $29 \%$ and therefore the soil state changes from dispersive soil to intermediate dispersive soil.

- At optimum dosage of ecosand, the durability of soil gives a good indication of performance of stabilized soil.

- At optimum dosage of ecosand, the additive act as fine material which fill some pores, and hence, increasing water holding capacity for soil.

\section{REFERENCES}

1. Mircea Aniculăesi*, Anghel Stanciu and Irina Lungu "Behavior of expansive soil treated with Eco-Cement.", Gheorghe asachi” Technical University of Iaşi, Faculty of Civil Engineering and Building Services.

2. Koteswara Rao.D, Pranav.P.R.T Anusha.M "Stabilization of expansive soil with rice husk ash, lime and gypsum- a experimental study”, International Journal of Engineering Science and Technology (IJEST).

3. Keertana.B, Sini Sara Mani, M, Thenmozhi (Karpagam University, CBE). "Utilization of eco sand and fly ash in aerated concrete for a mixer design” International Journal of Engineering Science and Technology (IJEST).

4. Nurhayat Degirmencia, Arzu Okucub, Ayse Turabib "Application of phosphogypsum in soil stabilization" Building and Environment 42 (2007) 3393-3398.

5. Dr.Akshaya Kumar Sabat "A study on some geo technical properties of lime stabilized expansive soil-quarry dust mixes" iter, SOA University.

6. D.Neeraja." Influence of lime \& plastic jute on strength \& CBR characteristics of expansive soil" GJRE.

7. Dr. Robert M. Brooks" Stabilization of expansive soil using flyash \& rice husk ash" ISSN: 2076-734X, EISSN: 20767366.

8. Felix Ling Ngee Leh, 2 Rafidah binti Robani" A study of unconfined of a chemically stabilised soil with cement and timber industrial ash (TIA) Prosiding Kebangsaan Awam '07 ", Langkawi, Kedah, 29hb-3lhb Mei 2007.

9. Dr.Suhail A., A. Khattab, Khawla A, K. Al-Juari and Ibrahaim M. A. Al-Kiki "Strength, Durability And Hydraulic Properties Of Clayey Soil Stabilized With Lime And Industrial Waste Lime”, University of Mosul- College of Engineering.

10. Dr. Suhail Idrees Khattab and Mohammed Mukhlif Aljobouri "Effect of Combined Stabilization by Lime and Cement on Hydraulic Properties of Clayey Soil Selected From Mosul Area”, University of Mosul- College of Engineering. 
11. T.S. Umesha, S.V. Dinesh, and P.V. “Control of dispersivity of soil using lime and cement” International Journal of Geology.

12. Bhuvaneshwari, S. \& Soundara, B. "Stabilization and Micro structural Modification Of Dispersive Clayey Soils" IIT Madras, Chennai, Tamil Nadu, India.

13. Aravind Pedarla "Durability Studies On Stabilization Effectiveness Of Soils Containing Different Fractions Of Montmorillonite" University of Texas at Arlington.

14. Delwyn G. Fredlund, Daichao Sheng, and Jidong Zhao" Estimation of soil suction from the soil-water characteristic curve" University of Newcastle 3.

15. Koteswara Rao. D, Pranav. P. R. T and Anusha. M" stabilization of expansive soil with rice husk ash, lime and gypsum -an experimental study” International Journal of Engineering Science and Technology (IJEST).

16. Ramteke, balwant, and ak saxsena. "strengthening black cotton soil with rha and moorum for pavement subgrade." international journal of applied and natural sciences (ijans) 5.4 (2016):6570.

17. Hegazy, alnos ae. "chemical analysis of wastewater-contaminated ground soil in arar, saudia arabia." international journal of civil engineering (ijce) 3.2 (2014):1524.

18. Ash-shu'ara, marafa salman, and ajayi wale. "effect of addition of coarse sand particles on engineering properties of clay soil." international journal of civil, structural, and environmental and infrastructure engineering research and development (ijcseierd) 8.4 (2018):2330.

19. Aulakh, deepinder singh, sarvesh kumar, and ramandeep singh cheema. "unconfined compressive strength of cement stabilized pond ash." international journal of civil, structural, and environmental and infrastructure engineering research and development (ijcseierd) 8.3 (2018):714.

20. Rajagopal, deepthy, and mathews m. paul. "durability study of self-compacting concrete using manufactured sand." impact: international journal of research in engineering \& technology (impact: ijret) 2.9 (2014): 4550. 